\title{
Effect of Congenital C4-5 Synostosis on Adjacent Mobile Segments: Radiographic Assessment
}

\author{
Myung-Sang Moon ${ }^{1,2}$, Won Rak Choi ${ }^{1,2}$, Hyuon Gyu Lim ${ }^{1,2}$, Seong Man Jeon ${ }^{1,2}$, Chang Geun Yu ${ }^{1,2}$ \\ ${ }^{I}$ Moon-Kim's Clinical Institute of Orthopedic Research, Seoul; ${ }^{2}$ Department of Orthopedic Surgery, Cheju Halla General Hospital, Jeju, Korea
}

\section{Study Design: Prospective case series.}

Purpose: To assess the corporal morphology of the fused body and adjacent segment conditions.

Overview of Literature: It is known that two fused vertebral bodies take the similar shape of the single body with inwaisting, with or without caudal flaring of the fused body, and that the fused body can cause the fusion disease at the adjacent segment that can be a risk factor for potential neurological compromise.

Methods: Radiograms of the 11 study subjects (six men and five women), aged 22-90 years who visited the outpatients' clinic for various neck complaints without trauma history were examined. C4-5 synostosis was an incidental finding in all the subjects.

Results: All the fused bodies were inwaisted and had anterior caudal breaking but no interior corporal flaring. Adjacent segment disease was not found in eight patients aged $<40$ years. Disk degeneration was found at C3 -4 and C5-6 in three patients each and at C6-7 in two patients. Disk degeneration was limited to the adjacent segments.

Conclusions: Degenerative disk changes are associated with the natural aging process, and the corporal morphology of the fused vertebral becomes inwaisted similar to that in the single vertebrae.

Keywords: Synostosis; Cervical spine; Congenital; Spondylosis

\section{Introduction}

It is known that block vertebrae of the cervical spine are a rare but well-known condition. Some authors consider congenital cervical block vertebrae as an accidental radiographic finding that is not related to any disease, while others conjecture that the block vertebrae might cause secondary degenerative changes and mobility disturbance of the adjacent segments. Based on this information, we designed the current study. The authors noticed that each motion segment's response was biomechanically different owing to the differed sagittal alignment at each level, the difference in natural mobility, their bearing load size, and axis [1-3].

The current study is one of the serial study projects at the different fused levels and is to assess the normally aligned $\mathrm{C}_{4-5}$ synostosis on the adjacent segment. This is the fourth study by the author of the current study.

\section{Materials and Methods}

Radiographs of 11 patients (six men and five women)

Received Feb 1, 2021; Accepted Mar 17, 2021

Corresponding author: Myung-Sang Moon

Moon-Kim's Clinical Institute of Orthopedic Research, \#14-105, 45 63-ro, Yeongdeungpo-gu, Seoul 07344, Korea

Tel: +82-2-780-5387, Fax: +82-2-785-6065, E-mail: msmoonos@hotmail.com 


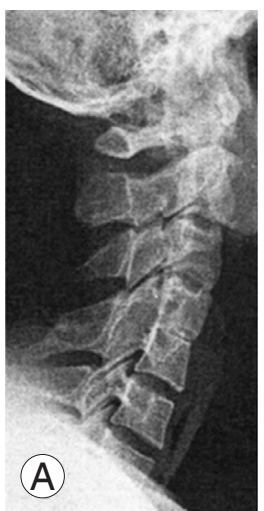

$22 \mathrm{yr} / \mathrm{M}$

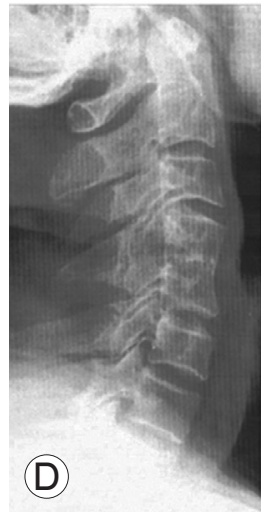

$38 \mathrm{yr} / \mathrm{M}$

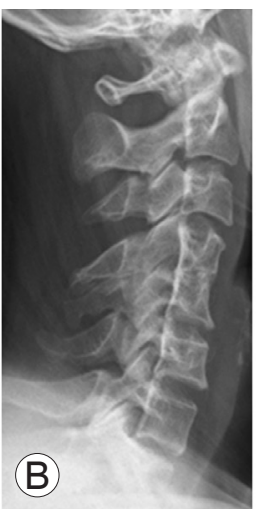

$27 \mathrm{yr} / \mathrm{F}$

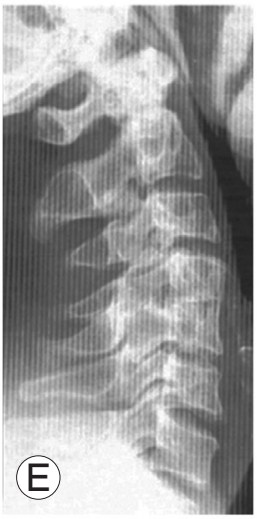

$42 \mathrm{yr} / \mathrm{M}$

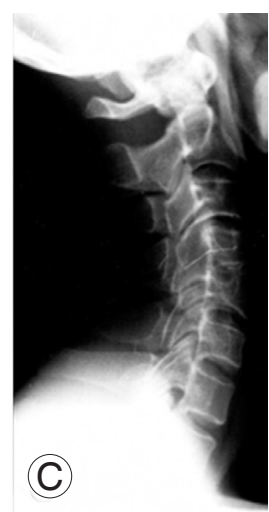

$32 \mathrm{yr} / \mathrm{M}$

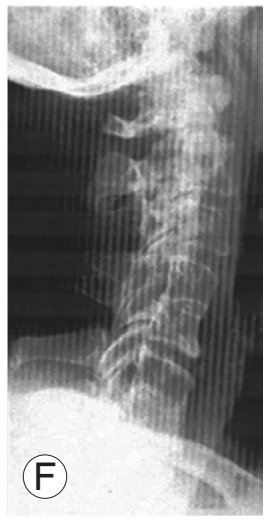

$45 \mathrm{yr} / \mathrm{M}$

Fig. 1. (A-F) Lateral radiographs of six patients with congenital $\mathrm{C}_{4-5}$ synostosis show the inwaisted fused vertebrae without disc degeneration in any of the adjacent mobile segments. $M$, male; $F$, female.

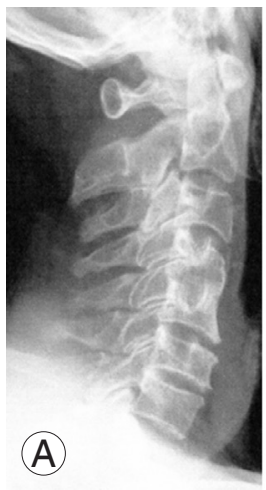

56 yr/M

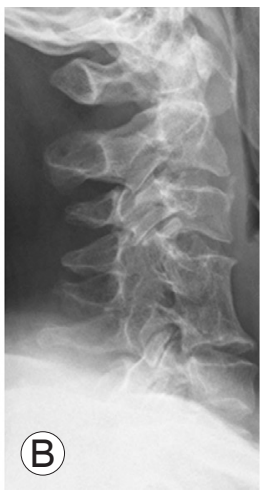

$62 \mathrm{yr} / \mathrm{F}$

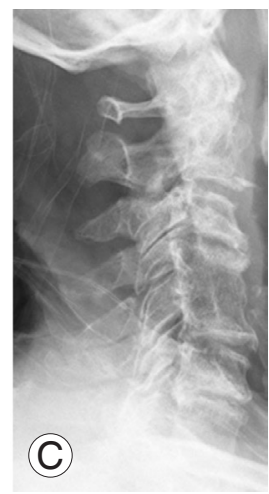

$90 \mathrm{yr} / \mathrm{F}$

Fig. 2. Sagittal radiographs of three patients with congenital C4-5 synostosis (A-C), aged from 56 to 90 years, show slightly inwaisted fused vertebral body and slightly flared lower part of the fused body. But severe spondylotic changes were observed at two proximal and caudate discs, respectively. $M$, male; F, female.

aged 22-90 years with congenital synostosis of $\mathrm{C}_{4-5}$ were investigated (Figs. 1-3). All the cases were accidentally

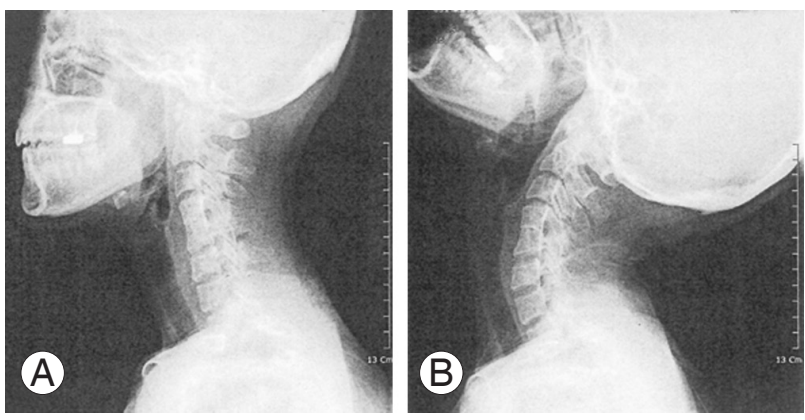

Fig. 3. In both cases (A, B), there are no adjacent segment disc degeneration.

while performing diagnosed on radiography (Table 1). Severity of disk degeneration was expressed as follows: normal height as -, narrowing suspected as $( \pm)$, mild narrowing $(<25 \%)$ as + , moderate narrowing $(50 \%)$ as ++ , relatively severe narrowing $(75 \%)$ as +++ , and very severe narrowing (over $75 \%$ ) as ++++ .

\section{Results}

None of the patients ostensibly showed a short neck. Block vertebral body showed more remarkable inwaisting and anterior inferior corporal lipping. Among eleven patients, only three aged $>45$ years developed disk narrowing in the two cranial and two caudal adjacent segments (cranial: $\mathrm{C}_{2-3}$ and $\mathrm{C}_{3-4}$; caudal: $\mathrm{C}_{5-6}$ and $\mathrm{C}_{6-7}$ ). The severity of disk degeneration ranged from \pm (suspected early disk degeneration) to +++ (relatively severe disk narrowing). The incidence of age-related (decadal) disk degeneration is shown in Table 2. Only three patients aged $>51$ years showed disk degeneration. However, only one patient aged $>81$ years showed relatively severe disk degeneration while two patients aged 56 years and 61 years showed \pm to + degree of degeneration.

\section{Discussion}

There have been numerous reports in the literature suggesting that the congenitally formed block vertebrae of a part of the cervical spine may alter the kinematics and cause extra-stress onto the adjacent non-fused segments, hypothetically resulting in early progressive disk degeneration. Generally, fusion may result in increased intradiskal pressure at the adjacent levels and would impair the nutrition of the disk; however, this interpretation is conflicting. To clarify the issue, the current study investigated the 
Table 1. Disc conditions of cephalad and caudad levels in patients with congenital $\mathrm{C}_{4-5}$ synostosis

\begin{tabular}{|c|c|c|c|c|c|c|c|c|c|}
\hline \multirow{2}{*}{ No. } & \multirow{2}{*}{ Patients } & \multicolumn{7}{|c|}{ Level of cervical spinal segments } & \multirow{2}{*}{ Remarks } \\
\hline & & $\mathrm{CO}-1$ & $\mathrm{C} 1-2$ & $\mathrm{C} 2-3$ & C3-4 & C5-6 & C6-7 & C7-T1 & \\
\hline 1 & Chang SY (2/M) & - & - & - & - & - & - & - & Slightly inwaisted fused vertebral body \\
\hline 2 & Sohn SY (22/M) & - & - & - & - & - & - & - & Slightly inwaisted fused vertebral body \\
\hline 3 & Chung SY (27/F) & - & - & - & - & - & - & - & \\
\hline 4 & $\operatorname{Kim} B E(31 / F)$ & - & - & - & - & - & - & - & \\
\hline 5 & Sohn HK (38/M) & - & - & - & - & - & - & - & \\
\hline 6 & Sohn CM (42/M) & - & - & - & - & - & - & - & \\
\hline 7 & Chung MH (45/M) & - & - & - & - & - & - & - & \\
\hline 8 & Bae KS (56/M) & - & - & - & \pm & \pm & - & - & \\
\hline 9 & $\operatorname{Kim} S S(61 / F)$ & - & - & - & - & - & + & - & \\
\hline 10 & Lee M0 (62/F) & - & - & - & - & - & - & - & Inwaisted body \\
\hline 11 & Lee KS (90/F) & - & - & + & +++ & + & ++ & - & Slight loss of lordosis \\
\hline Total & & 0 & 0 & 1 & 2 & 2 & 1 & 0 & Disc degeneration in 6 segments totally \\
\hline
\end{tabular}

Disc space conditions: normal height, -; suspected, \pm ; mild narrowing $(25 \%),+$; moderate narrowing $(50 \%),++$; relatively severe narrowing $(75 \%)$ : +++; very severe narrowing (over $75 \%$ ), ,+++.

$\mathrm{M}$, male; F, female.

Table 2. Age-related distribution of the spondylotic mobile segments in 11 patients (six males and five females) with congenital $\mathrm{C}_{4-5}$ synostosis

\begin{tabular}{|c|c|c|c|c|c|c|c|c|c|}
\hline \multirow{3}{*}{ Patients age group (decades), yr } & \multicolumn{8}{|c|}{ Observed spondylosis levels in each patient } & \multirow{3}{*}{ Remarks } \\
\hline & \multirow{2}{*}{ Male/female } & \multicolumn{7}{|c|}{ Mobile cervical segments } & \\
\hline & & $\mathrm{CO}-1$ & C1-2 & C2-3 & C3-4 & C5-6 & C6-7 & C7-T1 & \\
\hline Below 20 & 0 & - & - & - & - & - & - & - & \\
\hline $21-30$ & $2(1 / 1)$ & - & - & - & - & - & - & - & \\
\hline $31-40$ & $3(2 / 1)$ & - & - & - & - & - & - & - & \\
\hline $41-50$ & $2(2 / 0)$ & - & - & - & - & - & - & - & \\
\hline $51-60$ & $1(1 / 0)$ & - & - & - & \pm & \pm & - & - & \\
\hline $61-70$ & $2(0 / 2)$ & - & - & - & - & - & + & - & Inwaisted body \\
\hline $71-80$ & 0 & - & - & - & - & - & - & - & \\
\hline $81-90$ & $1(0 / 1)$ & - & - & + & +++ & + & ++ & - & \\
\hline Over 90 & 0 & - & - & - & - & - & - & - & \\
\hline Total & $11(6 / 5)$ & 0 & 0 & 1 & $2(1 \pm, 1+++)$ & $2(1 \pm, 1+)$ & $2(1+, 1++)$ & 0 & \\
\hline
\end{tabular}

Normal disc, -; disc degeneration suspected, \pm ; mild disc narrowing $(<25 \%)$, +; moderate narrowing $(<50 \%),++$; relatively severe narrowing $(<75 \%)$, +++ ; very severe narrowing (over 75\%), ++++.

morphology of the fused vertebrae and degeneration of the possible adjacent disk. Leivseth et al. [4] showed that the caudal adjacent disk height of the fused vertebrae was significantly reduced, while the height of the cranial adjacent disk was normal. However, in the current authors' series, both the cranial and caudal adjacent disks were affected. Thus, the result of the current authors' study does not accord with the observations of Leivseth et al. [4].

Generally, it has been conjectured that fusion might result in an unphysiological motion pattern of adjacent segments and that the former motion of the fused segment might be transferred to the open cranially or caudally adjoining segments. However, the presented evidence is conflicting, and it is difficult to speculate on the detrimen- 
tal effect of block vertebra on the adjacent mobile segment because the initial state of the mobile segments adjacent to the block vertebra is unknown.

Why a motion deficit due to fusion must be compensated only for in the adjacent segment instead of all open segments? In none of the subjects, hypermobility was complicated at the adjacent segment in the current authors' series. In the current series, only three patients (27.3\%) aged $\geq 56$ years developed spondylosis. Although the current authors cannot discern the contribution of synostosis apart from natural history, our data provide important information regarding adjacent segment disease (ASD).

\section{Conclusions}

Thus, it can be concluded that the degenerative disk changes are the reflection of the natural aging process and should not be labeled as ASD due to synostosis.

\section{Conflict of Interest}

No potential conflict of interest relevant to this article was reported.

\section{References}

1. Moon MS, Moon YW, Kim SS, Moon JL. Morphological adaptation of the bone graft and fused bodies after non-instrumented anterior interbody fusion of the lower cervical spine. J Orthop Surg (Hong Kong) 2006;14:303-9.

2. Moon MS, Kim SS, Lee BJ, Moon JL, Lin JF, Moon YW. Radiographic assessment of congenital C2-3 synostosis. J Orthop Surg (Hong Kong) 2010;18:1437.

3. Moon MS, Kim JM. The effect of mechanical forces on vertebral growth: a preliminary report. J West Pac Orthop Assoc 1974;11:1-26.

4. Leivseth G, Frobin W, Brinckmann P. Congenital cervical block vertebrae are associated with caudally adjacent discs. Clin Biomech (Bristol, Avon) 2005;20:669-74. 